\title{
Chapter 23 \\ Masonry Blocks from Lightweight Concrete on the Basis of Miscanthus as Aggregates
}

\author{
D. Waldmann, V. Thapa, F. Dahm, and C. Faltz
}

\section{Introduction}

In recent years, the political and social awareness about sustainability in different aspects of private and public environment has considerably increased. This trend has become a highly discussed topic in all kinds of branches, from chemical engineering and environmental science to resource management and construction engineering. One of the most important issues to solve in order to provide sustainability is the reduction of $\mathrm{CO}_{2}$ emissions. $\mathrm{CO}_{2}$ is a greenhouse gas that is emitted in enormous amounts into the atmosphere by human activities. Due to the resulting high concentration, the natural carbon cycle and the natural balance are influenced, as a considerable portion remains in the atmosphere for a fairly long time and retards the cooling of the Earth. This is known to increase atmospheric temperatures, resulting in the so-called "global warming" and, locally, "climate change".

In order to counteract this phenomenon, in the field of construction and building materials different measures for reduction of heating energy have been promoted and new requirements and directives have been successively issued by the authorities. Especially the requirements for thermal insulation of building envelopes have been intensively tightened, which has mainly driven the masonry construction sector to investigate new technical innovations and new insulation products in order to meet the growing requirements.

In Europe, the European Parliament issued the directive 2010/31/EU of 19 May 2010 on the energy performance of buildings. This directive sets as the objective for all European Member States that, until 2020, they shall take all appropriate measures

D. Waldmann $(\varangle) \cdot V$. Thapa

Laboratory for Solid Structures, University of Luxembourg, Esch-sur-Alzette, Luxembourg e-mail: daniele.waldmann@uni.lu

F. Dahm • C. Faltz

University of Luxembourg, Esch-sur-Alzette, Luxembourg 
for the transition of all new buildings and any transformation of existing buildings into nearly zero-energy buildings.

"Member States shall take the necessary measures to ensure that minimum energy performance requirements are set for building elements that form part of the building envelope and that have a significant impact on the energy performance of the building envelope when they are replaced or retrofitted, with a view to achieving cost-optimal levels."

In order to act on this directive, the Luxembourgish government has established new objectives and requirements which demand that from 2017 on, every construction of new residential buildings should be built according the passive house standards.

These requirements force the manufacturers of masonry building materials to launch new and innovative products into the market in order to meet the required thermal insulation properties. Additionally, the attractiveness of using "green" material as insulation has become more and more important as the market for organically sourced insulation material has experienced strong growth.

More precisely, one very promising organic material which could be used in order to meet the requirements is the pretreated "Miscanthus Giganteus" plant. In the following, the potential of masonry blocks from lightweight concrete on the basis of Miscanthus as aggregates is going to be discussed. Before initiating the topic of Miscanthus as aggregates in lightweight concrete, it is necessary to explain the main characteristics of this organic material.

Miscanthus is a natural, reed-like grass which can be found mostly in humid areas like African or South-East Asian regions. Originally, it is an energy crop from Japan and primarily was used as a sustainable and energy-rich raw material for biomass cogeneration plants due to its high calorific value and its favourable carbon balance during growth. Additionally, it was found that Miscanthus presents advantages in conjunction with concrete as it is a C-4 plant and therefore shows a higher photosynthetic efficiency and lower water use requirements than other plants. Furthermore, this plant needs 2-3 times less water for growth than other plants and also can be grown on barren grounds.

These characteristics make Miscanthus very interesting for its use in lightweight concrete mixtures. In the following, the material characteristics of concrete based on Miscanthus aggregates for use within structural elements are analysed. It is discussed if the material properties of this concrete, especially its compressive strength and its heat conductivity, will fulfil the requirements necessary to use it within structural insulating masonry blocks.

\footnotetext{
${ }^{1}$ Excerpt from Article 4 of directive 2010/31/EU of the European Parliament and of the council of 19 May 2010 on the energy performance of buildings [1]
} 


\section{State of the Art}

In general, water, cement and organic aggregates do not bond strongly together due to stability issues of the organic plant, as its behaviour in the bond is usually unpredictable. However, under specific conditions, Miscanthus becomes a useful aggregate for concrete mixtures. The outer shell of Miscanthus is covered with a tiny silicon layer which normally stabilises the plants. This characteristic, respecting certain specific conditions, allows a concrete mixture using Miscanthus aggregates to be prepared. Concrete made out of Miscanthus has the following advantages when using it within concrete masonry blocks:

Firstly, such mixtures enable better insulation characteristics leading to a reduction of the thickness of the concrete masonry blocks. Secondly, this building material provides due to its natural insulation characteristics an improved protection against summer overheating. The durability of this material is given due to the mineral bonding of Miscanthus which thus increasingly hardens. Furthermore, a comfortable sound insulation is given by the numerous pores in the concrete containing Miscanthus aggregates. Fire protection is increased due to the fact that more energy has to be supplied to the material as it can be extracted from it, which means that Miscanthus is not self-combustible. Finally, it constitutes a sustainable alternative to natural resources like sand and gravel in a concrete mixture.

These properties are naturally given by the characteristics of Miscanthus, but in order to use this building material in structural load-bearing elements, the objective is to provide reasonable compression strengths combined with good thermal resistance.

The combination of concrete with organic materials is long known but the main issue is that the organic material has to be pre-mineralized in order to reduce its water absorption characteristics in favour of the actual concrete reactions. This process is very costly and time-consuming as the material has to be mixed with the mineraliser in a separate work step and, in addition, the mineraliser itself is very expensive and often harmful to the environment. In order to prevent such an expensive and inefficient process, there are alternative processes where the mineraliser is incorporated during mixing, thus resulting in lower compression strengths and durability due to weaker bonding between the organic material and the binder. However, this process remains economically interesting as it skips the step of drying after the mineralisation process, saving time and money.

Different processes already exist for concrete mixtures using organic, plantbased additives. In these guidelines, the composition of concrete and mortar made out of organic admixtures, a hydraulic binder, water and a mineraliser is described. Generally, in these processes, the main intention is to prevent the costly and time-consuming procedure of direct pre-mineralisation of organic materials before combination with the hydraulic binder. Most often, the solution is to use calcium carbonate $\left(\mathrm{CaCO}_{3}\right)$ during the mixture of the cement with the organic additives. It works like a mineraliser on the surface of the organic additives during mixing, and the better and finer $\mathrm{CaCO}_{3}$ is distributed, the more efficient the cement bonding 
becomes. As a consequence, better compression and bending tensile strengths can be achieved. However, if the calcium carbonate does not react well, the strength values may strongly vary and the required final strengths would not be fulfilled.

This has been tested in the following (see Sect. 23.4) and different types of mineralisers like calcium carbonate and calcium hydroxide has been used as mineraliser. It came out that the mixtures presented varying strengths and thermal resistances after 56 days.

\section{Description of Insulation Concepts and Concrete Masonry Block Types}

Before explaining the different concepts, it is necessary to mention that lightweight concrete blocks themselves have insulation properties as they are made with lightweight aggregates that contain more air spaces than other aggregates and therefore conduct heat more slowly than normal or heavyweight concrete blocks.

\section{Insulation Concepts}

As the intention is to develop masonry blocks from Miscanthus concrete, an overview of different concepts of insulating masonry walls is given and their characteristics are explained.

The first concept is to place the insulation on the exterior face of masonry walls. As masonry has more mass, it is able to absorb and store more heat and therefore this concept would allow the masonry to absorb heat during day time and release it during night. The insulation material is attached with adhesive or with mechanical fasteners to the masonry. Normally, it is covered with a weather-resistant finishing coating in order to guarantee additional protection, resistance and longer durability.

The second concept is to incorporate insulation in the cores of the concrete block. The insulation material, such as granular materials, polystyrene inserts or foam, must be chosen accordingly to the use of the wall, as its amount is limited by the open core area. The advantage is that the total thickness of the exterior wall is reduced; however, due to its limited protection, this kind of structure is highly susceptible to thermal bridges.

The third concept is to attach a suitable, rigid insulation material to the interior side of masonry walls. They are usually combined with panelling or gypsum boards for finishing. This method is mostly used in older buildings for simple retrofitting as, due to the position of the insulation, the wall's thermal mass is located outside the insulation envelope.

The forth concept uses the air space in a so-called cavity wall as an insulation layer. This will increase the thermal resistance of the wall as granular materials, rigid foam boards and pumping foam can be placed inside the cavity. The advantages are 
that this concept maintains the existing wall thickness, easy to instal, cheaper than exterior or interior wall insulation and reduces condensation. In this case, the insulation fills the gap, keeping the warmth in, so that the water vapour in the air cannot condense on the cold wall.

\section{Concrete Insulation Masonry Block Types}

Concrete insulation masonry blocks are lightweight structural elements used in building construction which combine, in a single section, load-bearing as well as insulating functions. These blocks usually are rectangular and can be solid or have one or several hollow spaces. In the following, different block types are presented and later the main issues are discussed.

Table 23.1 lists the different types of concrete bricks including a short description illustrated in Fig. 23.1:

The main issue with concrete bricks is that currently it is only possible to increase either the insulation characteristics or the load bearing capacity of the concrete bricks. The combination of both characteristics is always related to the choice between

Table 23.1 Types of masonry concrete block

\begin{tabular}{|c|c|}
\hline \multirow[t]{2}{*}{ A } & Full brick \\
\hline & Lightweight concrete with open structure (expanded clay) \\
\hline \multirow[t]{2}{*}{ B } & Full brick \\
\hline & Lightweight concrete with open structure (natural pumice) \\
\hline \multirow[t]{2}{*}{$\mathrm{C}$} & Full brick \\
\hline & Lightweight concrete with open structure (natural pumice + expanded clay) \\
\hline \multirow[t]{2}{*}{$\mathrm{D}$} & Full brick \\
\hline & Lightweight concrete with open structure (natural pumice + expanded clay) \\
\hline \multirow[t]{2}{*}{$\mathrm{E}$} & Brick to be filled with concrete $\mathrm{C} 16 / 20$ \\
\hline & $\begin{array}{l}\text { EPS-exterior insulation, interior shell of lightweight concrete with lost formwork } \\
\text { of concrete (expanded clay) }\end{array}$ \\
\hline F & Hollow brick with an cork insulation at the inner side \\
\hline \multirow[t]{2}{*}{ G } & Full brick \\
\hline & Lightweight concrete with open structure (natural pumice) \\
\hline \multirow[t]{2}{*}{$\mathrm{H}$} & Full brick \\
\hline & Lightweight concrete with open structure (expanded clay) and integrated insulation \\
\hline I & Aerated concrete-planar brick \\
\hline \multirow[t]{2}{*}{$\mathrm{J}$} & Full brick \\
\hline & Lightweight concrete with open structure (natural pumice + expanded clay) \\
\hline K & Aerated concrete-planar brick (different producer from I) \\
\hline \multirow[t]{2}{*}{$\mathrm{L}$} & Insulating sandwich brick with interior insulation \\
\hline & Lightweight concrete with open structure (expanded clay) \\
\hline
\end{tabular}




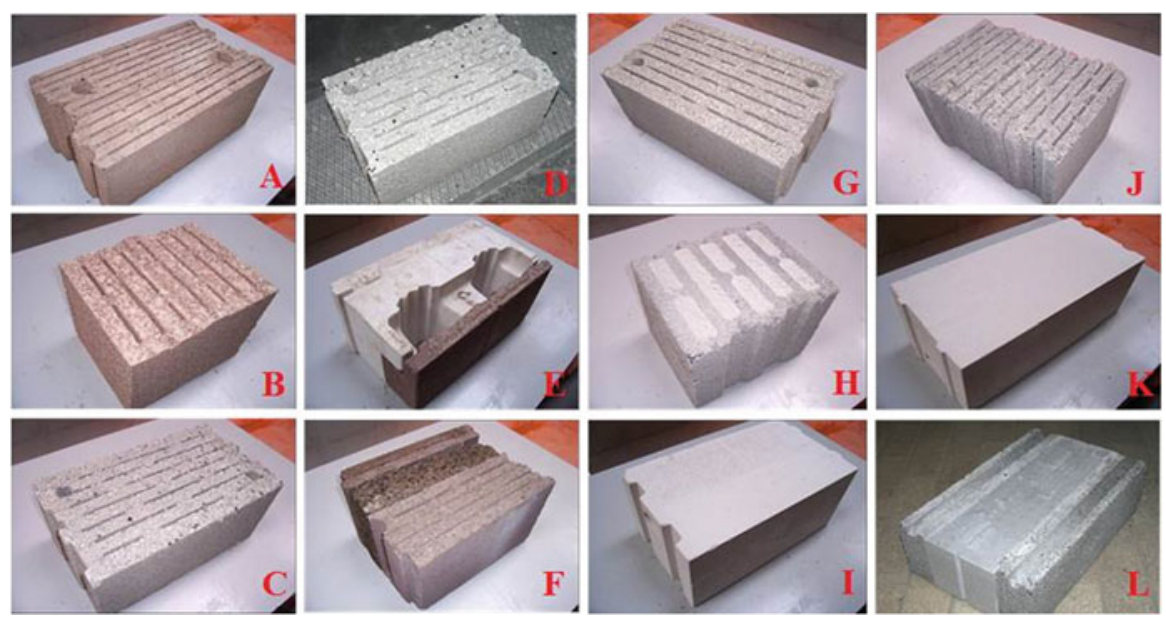

Fig. 23.1 Different types of concrete bricks

increasing the insulation properties by accepting losses in carrying capacities or, on the contrary, accepting a reduction of thermal properties in favour of more load capacity.

More precisely, if we consider one cross section of a concrete brick in terms of heat losses, three major thermal effects are significant: conduction, convection and radiation. Radiation can only be reduced by incorporating reflective insulation, which is an uneconomical and costly method, or by increasing the air space which raises block sizes. Therefore radiation is often reduced using other constructive elements.

The problem of conduction and convection when using concrete bricks can be reduced by applying lightweight concrete with lower thermal conductivity or by increasing the heat conduction path using several successive air spaces.

For example, the type A concrete brick (Fig. 23.1) has small, unfilled airspaces and therefore is exposed to lower convection effects, but higher conduction effects than for example the concrete section of the block type H (Fig. 23.1) which is exposed to higher convection, but lower conduction. Therefore in order to reduce convection effects, the air spaces are filled with insulation material.

As it can be seen, new concepts and technologies are needed to have an overall well-performing block composition in terms of combining insulation and load bearing capacities. In recent years, several studies and investigations on new materials and new compositions have been launched and consistently developed further (Leufgens 2010; Sagmeister 1999; Kvande 2001; Voß 2009). A promising conception would be the use of lightweight concrete made of Miscanthus aggregates.

In the following, different masonry block concepts and characteristics are discussed in order to find the most suitable concepts in terms of insulation performances using Miscanthus lightweight concrete blocks. 


\section{Experimental Investigations}

The aim of this practical experiment was to develop new concrete formulations based on the renewable resource "Miscanthus" and lead primary investigations relating to the development of masonry bricks on the basis of this concrete. It is intended to develop a Miscanthus concrete with a certain load-bearing capacity and a low thermal conductivity. In order to cover a maximum of possibilities, different masonry block types were investigated and calculated. Finally, a conclusion is drawn on whether it is possible to develop masonry blocks incorporating Miscanthus concrete, which has a heat transition coefficient k equal or lower than $0.14 \mathrm{~W} / \mathrm{m}^{2} \mathrm{~K}$. This value is the minimal requirement for masonry wall insulations of passive house standards in Luxembourg as of January 2017.

\section{Description of the Methodology for the Development of the Concrete Mixtures}

In a first phase, different concrete mixtures were investigated to determinate the applicable relation between compressive strength and thermal conductivity. In general, load-bearing building materials possess high densities and low to no porosity which results in high thermal conductivity characteristics. On the other hand, insulation materials have low thermal conductivity but are not suitable to support high loads. Miscanthus has the characteristic of generating air spaces also in the compressed state due to its coarse and irregular form.

To be able to describe each fraction from the initial Miscanthus aggregate material, several grain-size distribution curves are established. Figure 23.2 shows the grain size distribution of three independent series by representing the through

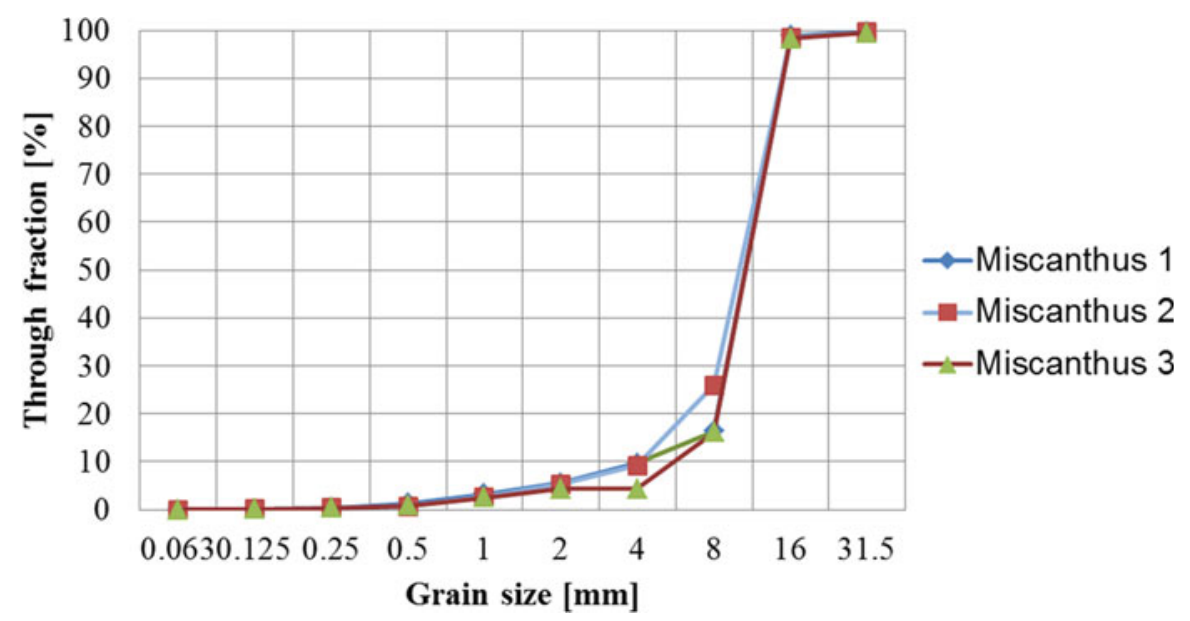

Fig. 23.2 Grain size distribution of three different Miscanthus series 
fraction for the different sieves. It can be seen that the grain size distribution of this natural material, which is cut at the moment of the harvest, shows some variations in the main fractions $2 / 4$ and $4 / 8$. The effect of these variations must be further investigated and have not been considered within the current study.

\section{Mineralisation of the Aggregates}

The Miscanthus aggregates have been treated by a mineraliser. The goal of this treatment is to seal the pores of the Miscanthus thereby mineralising them. With this treatment, the Miscanthus does not absorb too much water during the mixing process and after, and more water remains in the matrix to react with the cement particles. This will improve the bond characteristics between the Miscanthus aggregates and the cement, which has a positive effect on the strength development of the concrete. A mineraliser must have a very fine grain size distribution to be able to seal the pores.

As mineraliser, different substances like magnesite (magnesium carbonate, $\left.\mathrm{MgCO}_{3}\right)$, calcium hydroxide $\left(\mathrm{Ca}(\mathrm{OH})_{2}\right)$, chalk and calcium chloride $\left(\mathrm{CaCl}_{2}\right)$ have been used. Besides its effect of creating a better bond between the binder and organic substances and thus of improving compressive strength, magnesite improves the fire resistance and requires a relatively short hardening time. Calcium hydroxide is a colourless or white powder that is produced by the calcination of limestone at over $890^{\circ} \mathrm{C}$ out of the raw material calcium carbonate. To obtain calcium hydroxide, the calcium oxide is mixed with water, where it reacts highly exothermically. If calcium hydroxide is dissolved in water, it forms an alkaline solution. In the construction domain, calcium hydroxide is mainly used for mortar mixtures as well as mixed with sand to produce lime plasters. Chalk is a building material that acts as a binder and is mostly mixed with mortars. As a mineraliser, it forms a film on the surface of the Miscanthus aggregates what improves the bond behaviour. Calcium chloride is a salt that combined to cement presents the properties of an accelerator of the hydration process.

\section{Mixing Procedure}

The actual mixture has to be prepared in advance as a precise mixing time and sequence has to be followed (Fig. 23.3). First, the dry Miscanthus aggregates have been mixed with the whole mineraliser portion in order to create a homogenous mix. Then, one part of the water content as well as the entire cement portion has been added, followed by mixing again. At the end, the remaining water is added to the mixture in parallel to the mineraliser. For some mixtures, the sequence was intentionally deviated in order to investigate the influences of the deviation. Once the approach was clear, all the mixtures were realised strictly following the chosen mixing sequence. 

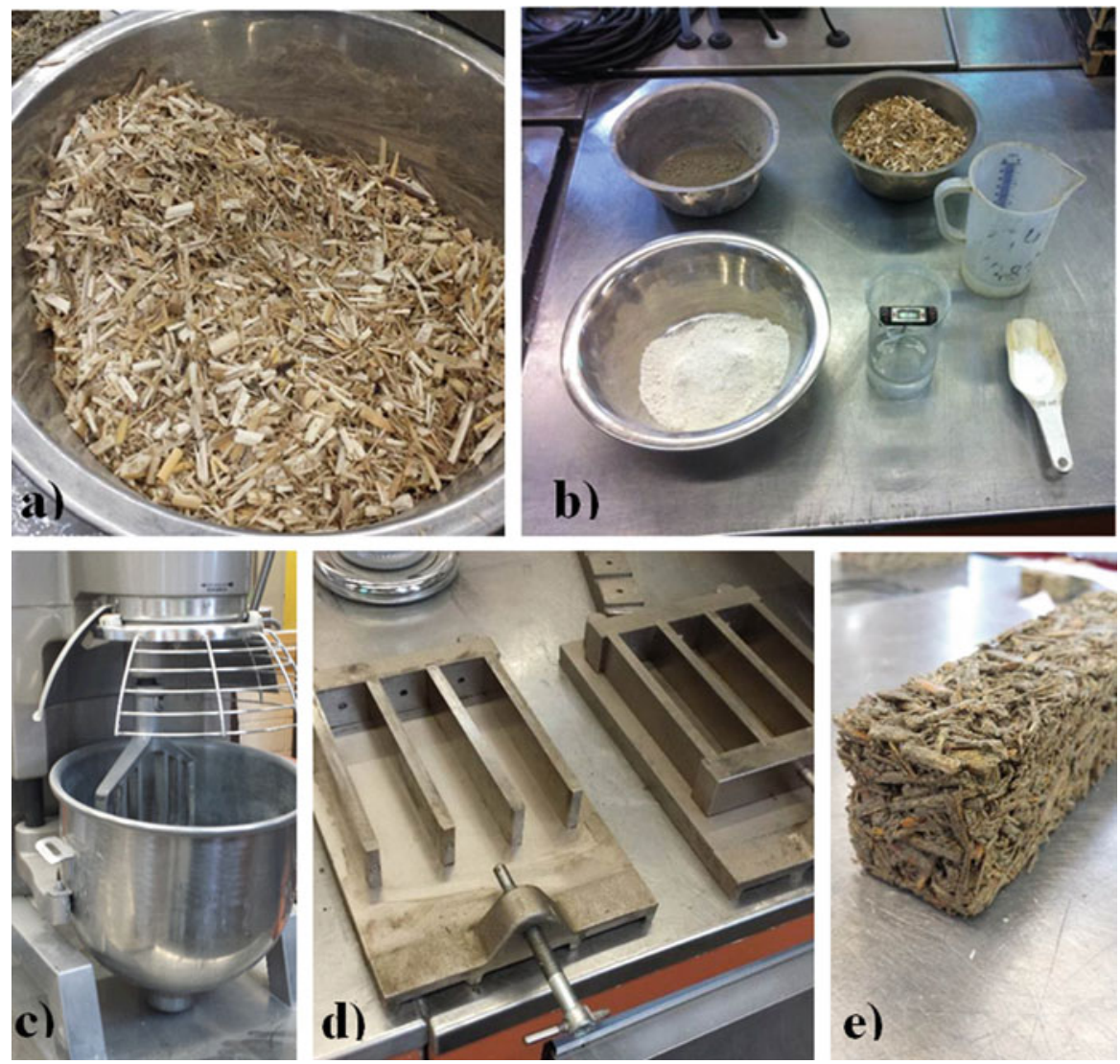

Fig. 23.3 (a) The loose Miscanthus in a bowl; (b) prepared components for the mixture; (c) the mixer; (d) standard prism-forms with the dimensions $4 / 4 / 16 \mathrm{~cm}$; (e) example of a hardened prism sample

The mixtures are filled in standard prim-forms with the dimensions 4/4/16 cm (Fig. 23.3) in order to have standard samples. These samples are stored for about 1 week and then retracted from the forms. Afterwards they are packed in wrapping film in order to keep the humidity in the concrete as there will be more water for the cement reaction. After 14 days, the samples are unpacked from the cellophane and dried by air.

\section{Description of the Methodology for Determination of the Material Properties}

\section{Apparent Density}

The apparent density $\left(\mathrm{kg} / \mathrm{m}^{3}\right)$ is determined by weighting the prisms and by evaluating their volume by measuring at different sections precisely the dimensions of the elements. This has been done on 14-day-old prisms. Hereby shrinkage has not been 

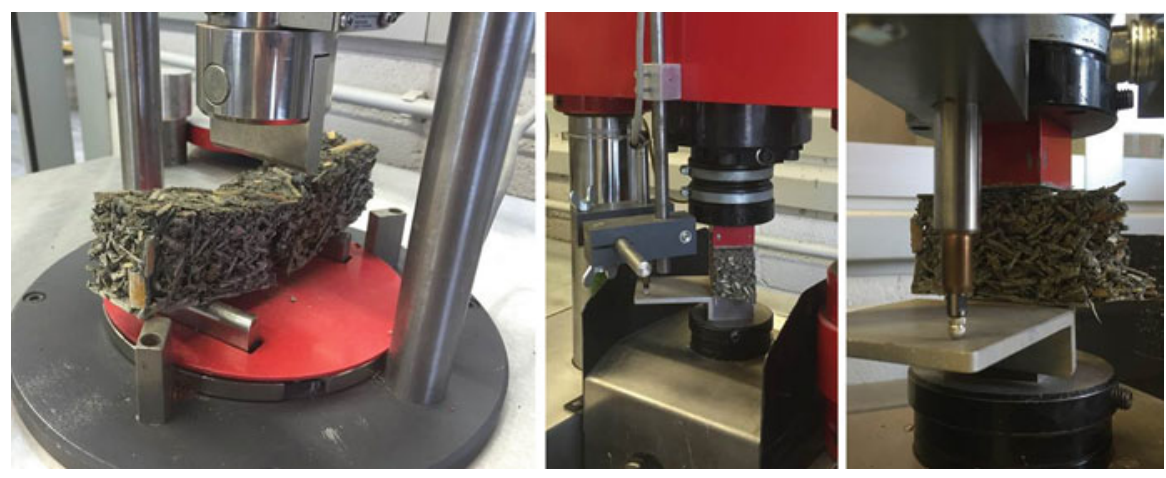

Fig. 23.4 Strength tests-Left side: setup for flexural strength test-Centre: setup for compression strength test—Right side: displacement transducer

taken into account as well as the water loss due to hardening of the elements with increasing age. So it can be assumed that with further ageing the apparent density of the prisms will still slightly change. This effect will also still have to be further investigated and has not been considered within the current study.

\section{Load-Deformation Behaviour}

The flexural and compression strength of the prims were determined according to the common cement testing standard DIN EN 196 Part 1 (Fig. 23.4). To evaluate the load-deformation characteristics of the prims in parallel to their compressive strength, an inductive displacement transducer measured simultaneously to the recorded loading the respective vertical deformation $\Delta h$. By relating this deformation to the initial height h of the element the elongation $\varepsilon=\Delta h / h$ was calculated. The compressive strength has been determined as the mean value out of three tests on identical prims that have hardened within one mould.

\section{Comparison of the Test Results of the Compressive Strength as a Function of Various Mineralisers, Water-Cement Ratios and Cement Content}

Firstly, the compression strengths of different concrete prisms treated with different mineralisers in the mixture were investigated.

In Fig. 23.5, the impacts of different pretreatment substances/mineralisers on the compressive strength are illustrated. As apart from adding various mineralisers the mixture remained unchanged, the differences of the strength-elongation behaviours 


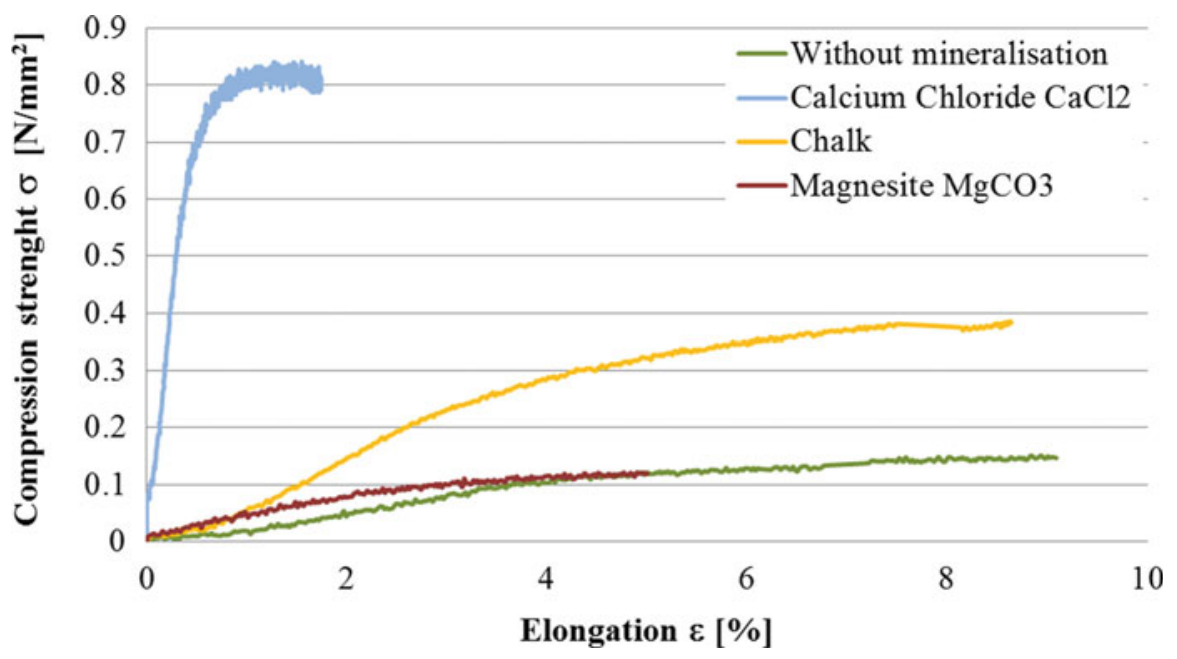

Fig. 23.5 Variation of mineralisation-Evolution of the compression strengths after 14 days of hardening

are considerable, especially for the mixtures with calcium chloride. So it can be concluded that the choice of mineraliser plays an important role in relation with the compression strength. Additionally, it can also be stated that calcium chloride $\left(\mathrm{CaCl}_{2}\right)$ is by far the most effective mineraliser as it has not only the highest compression strength but also presents the best bond behaviour between cement and Miscanthus aggregates as its strength-deformation curve shows the highest stiffness.

\section{Variation of Water-Cement Ratio}

In a second analysis, the strength-deformation behaviour of different concrete prisms with varying water-cement ratio in the mixture has been investigated.

In the first samplings, a low water-cement ratio has been chosen which led to the fact that these concrete mixtures achieved in general low compression strengths. Therefore different concrete mixtures with varying water-cement ratios were mixed and analysed. The most decisive factor is that there is enough water for the reaction of cement as Miscanthus aggregates are highly water absorbent.

As it can be considered in Fig. 23.6, also the water-cement ratio is, as expected, determinant for the resulting strength-deformation behaviour: a higher watercement ratio is favourable for higher compression strengths which goes along with an increase of the stiffness as the curves become steeper. 


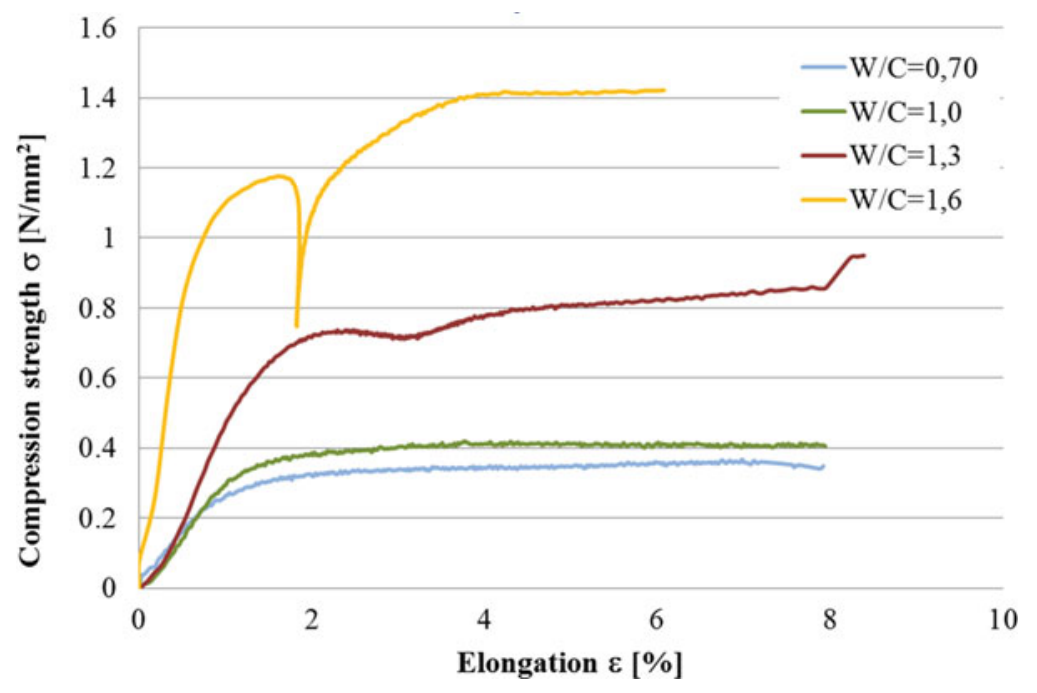

Fig. 23.6 Variation of water-cement ratio-Evolution of the compression strengths after 14 days of hardening

\section{Investigation of an Increase of the Cement Content}

In a third phase, the impacts of the cement content on the compression strength of different Miscanthus concrete prisms were investigated.

In Fig. 23.7, some interesting results can be observed. Predictably, with increasing cement content, the compression strengths increase, as generally a better bond can be expected because there is more cement present for the chemical reaction with water during the hydration process. In addition, it is remarkable that at same cement content, the concrete mixture with the highest water-cement ratio achieves higher compression strengths.

\section{Investigation of Micro-silica Addition}

Finally, micro-silica has been added to a mixture with a water-cement ratio of 1.0 containing $450 \mathrm{~kg} / \mathrm{m}^{3}$ cement and where calcium chloride has been used as mineraliser. Again, concrete prisms were investigated and the result can be seen in Fig. 23.8.

The compressive resistance as well as the stiffness of the mixtures with microsilica are similar to the mixtures containing $450 \mathrm{~kg} / \mathrm{m}^{3}$ cement of Fig. 23.7. An even higher strength development has been observed for mixtures without micro-silica with a higher water-cement ratio, which again proves the importance of this parameter. 


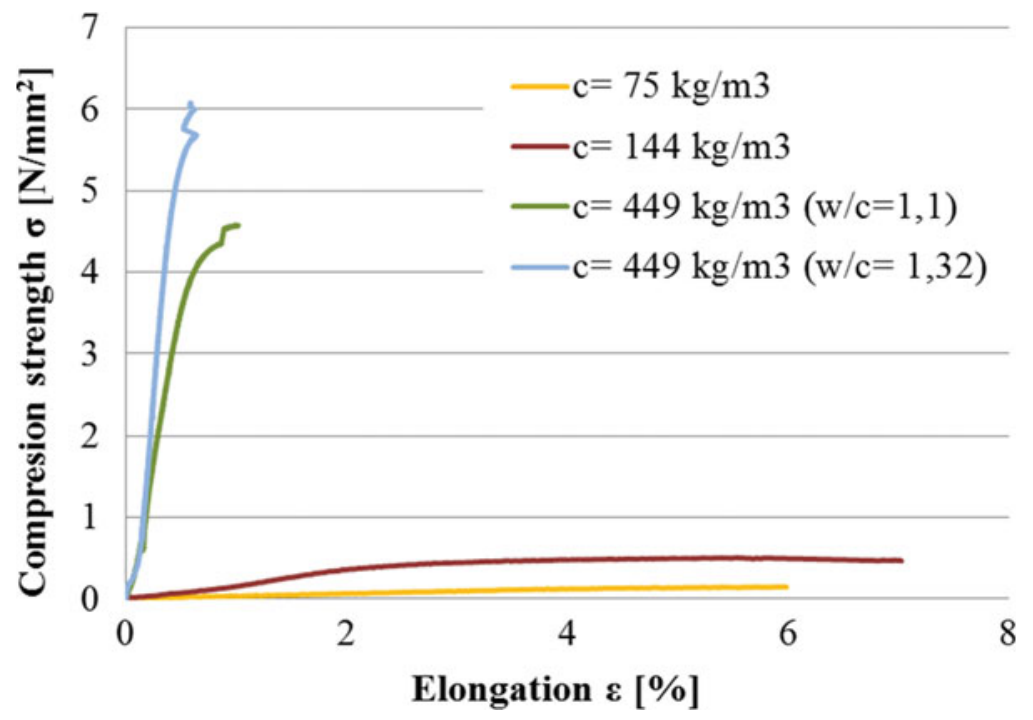

Fig. 23.7 Variation of cement content and water-cement ratio-Evolution of the compression strengths after 14 days of hardening

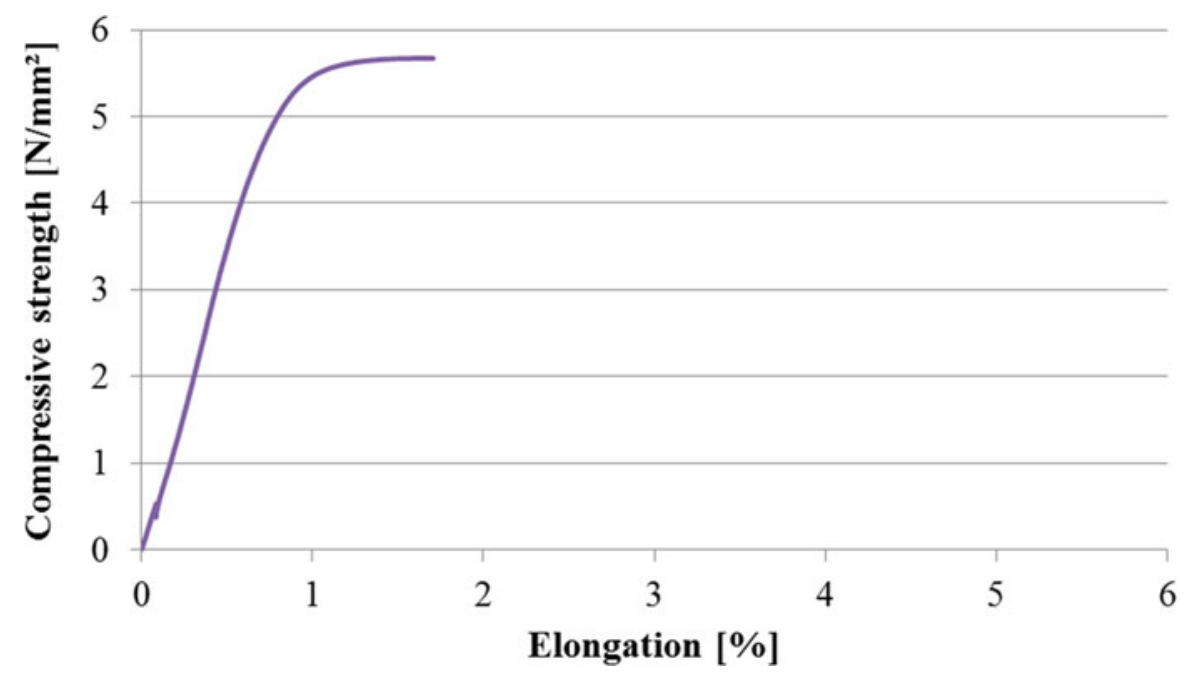

Fig. 23.8 Impact of an addition of micro-silica-Evolution of the compression strengths after 14 days of hardening 


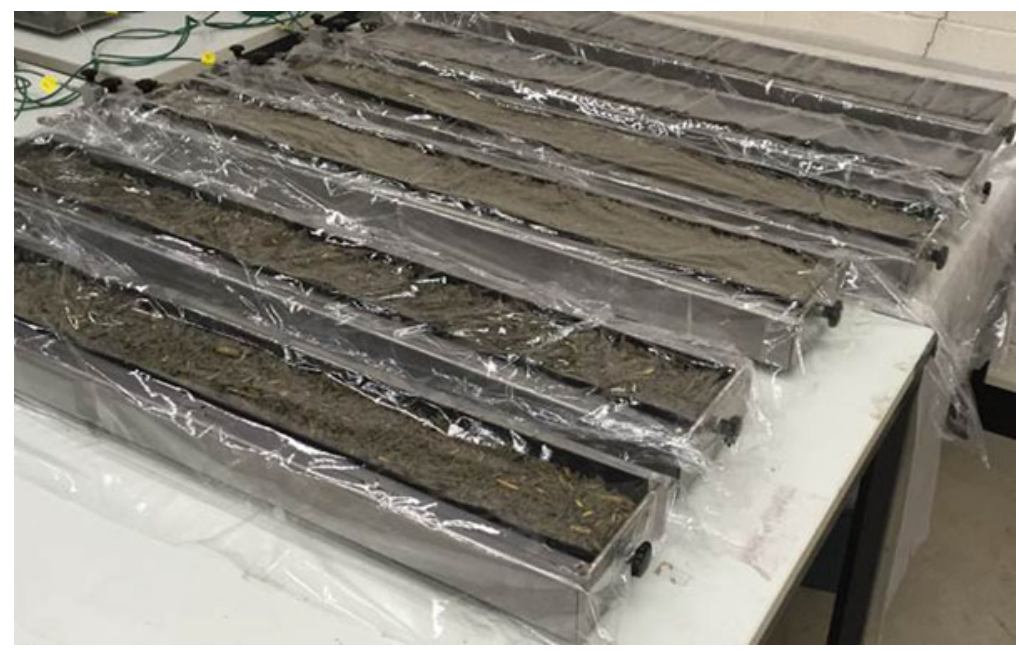

Fig. 23.9 Shrinkage channels

\section{Investigation of Shrinkage}

All concrete is subjected to shrinkage. This phenomenon is even more pronounced for lightweight mixtures on the basis of renewable water absorbing aggregates than for normal concrete mixtures. Therefore the shrinkage behaviour of the described mixtures has been analysed in shrinkage channels of a length of $1 \mathrm{~m}$ over several months (Fig. 23.9). Here, the horizontal elongation/retraction is continuously measured by displacement transducers installed at one end of the channels.

In Fig. 23.10 the measured elongation/retraction can be observed. In the first days, the elements showed an elongation due to water release. Then the deformation was constant for some days before the shrinkage of the elements started. At 60 days the most important part of the shrinkage retraction has occurred and the deformation behaviour remains more or less constant.

\section{Dependency of the Compression Strength on the Apparent Density}

In Fig. 23.11, the dependency of the compression strength on the apparent density for different analysed mixtures is evaluated.

The evaluation is carried out to examine if, like for other construction materials, a clear relation between the apparent density of the sample and the expected compressive strength is given. As expected this has been confirmed as the greater the density, the higher the compression strength of the sample. The determined values 


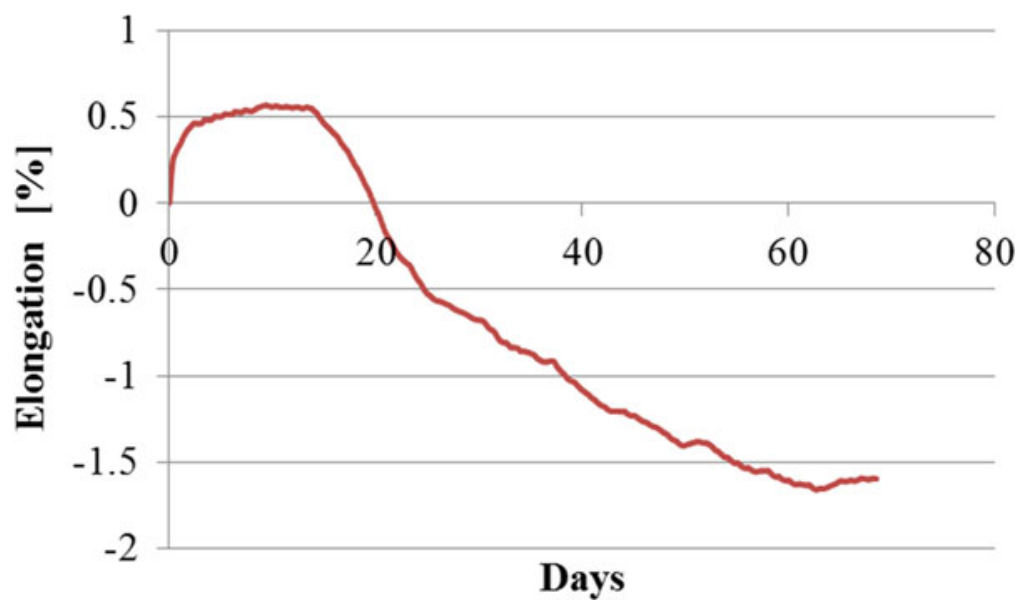

Fig. 23.10 Elongation/retraction behaviour of a mixture on the basis of Miscanthus aggregates

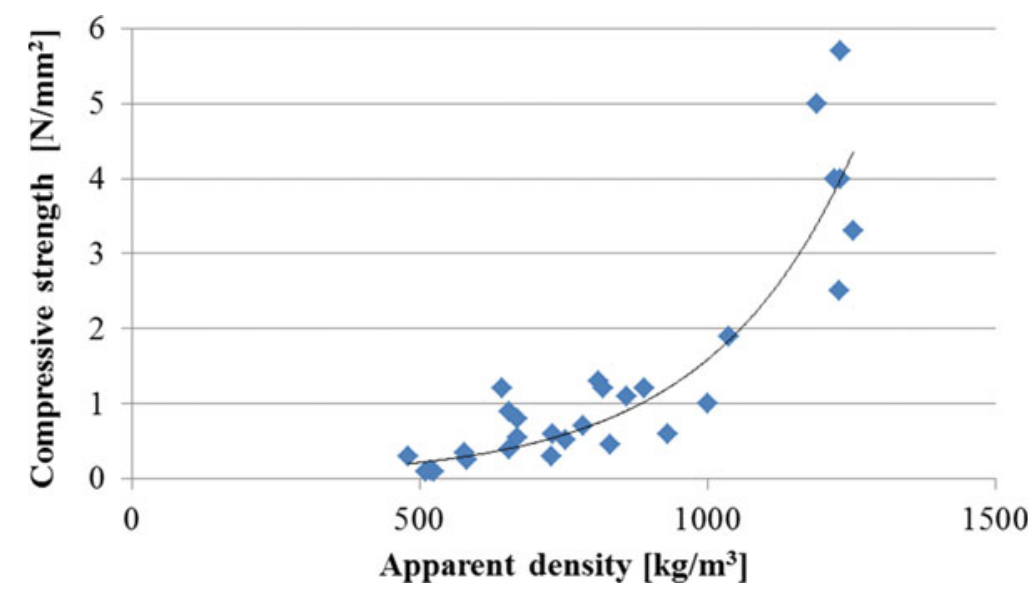

Fig. 23.11 Variation of compression strength in function of the apparent density-Evolution of the compression strengths related to the apparent density after 14 days of hardening (Dahm and Faltz, 2015)

can be placed along an exponential curve, but in order to confirm this behaviour it is necessary to evaluate more data in the future. However, this relation can be explained by the fact that a steady rise of the cement content leads to a gain in weight which conducts to higher strengths. Additionally, the water-cement ratio also has a considerable impact on the compressive strength as well as on the weight as the more water is available to the cement particles, the more hardened cement stone results, thus affecting the apparent density. 


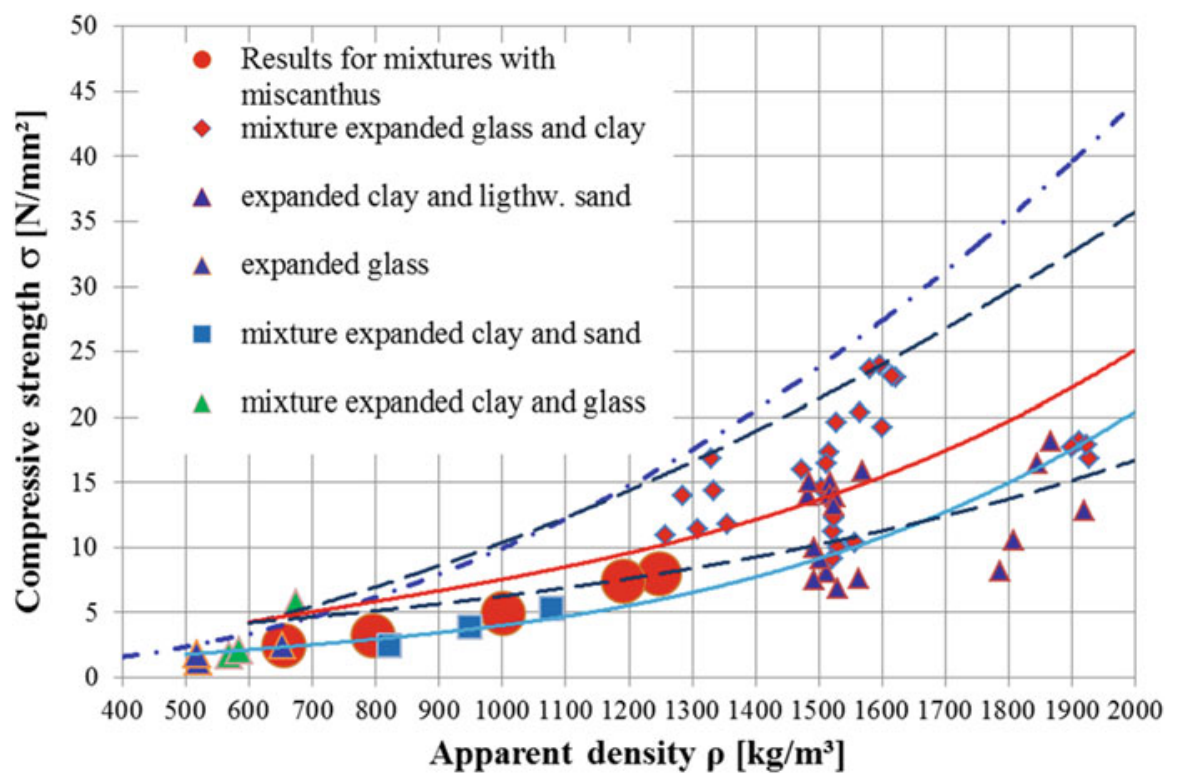

Fig. 23.12 Variation of the compression strength as a function of the apparent density: Comparison of Miscanthus concrete mixtures to other lightweight concrete mixtures (Leufgens 2010; Sagmeister 1999)

\section{Acceptance of Miscanthus Concrete Blocks as Light-Weight Concrete Blocks}

According to DIN V 18152:2003-2010, respectively according to DIN V 18152: 2003-2010, the minimum requirement with respect to compressive strength for masonry bricks is stated at $2.5 \mathrm{MPa}\left(2.5 \mathrm{~N} / \mathrm{mm}^{2}\right)$. The next step is to assess if this requirement is fulfilled by the Miscanthus lightweight concrete.

Figure 23.12 shows the relation between apparent density and compression strength of other lightweight mixtures in order to have some known references and state the position of Miscanthus concrete in the spectrum of existing similar options.

The previously evaluated relation points of the Miscanthus concrete are projected as red data points into Fig. 23.12, which allows us to make some conclusive observations about the aptness of Miscanthus concrete as lightweight concrete applicable for block fabrication.

Additionally to the red data points, a straight horizontal red line is drawn which represents the required minimal value of $2.5 \mathrm{MPa}$ in compression strength. It can be considered that from an apparent density of about $800 \mathrm{~kg} / \mathrm{m}^{3}$ on, the analysed Miscanthus concrete fulfils this requirement. In addition, it can be noticed that the Miscanthus is close to the laboratory test range of other lightweight concrete mixtures. The fabrication of Miscanthus in production lines could even result in better performance values in terms of compressive strength in relation to the apparent 

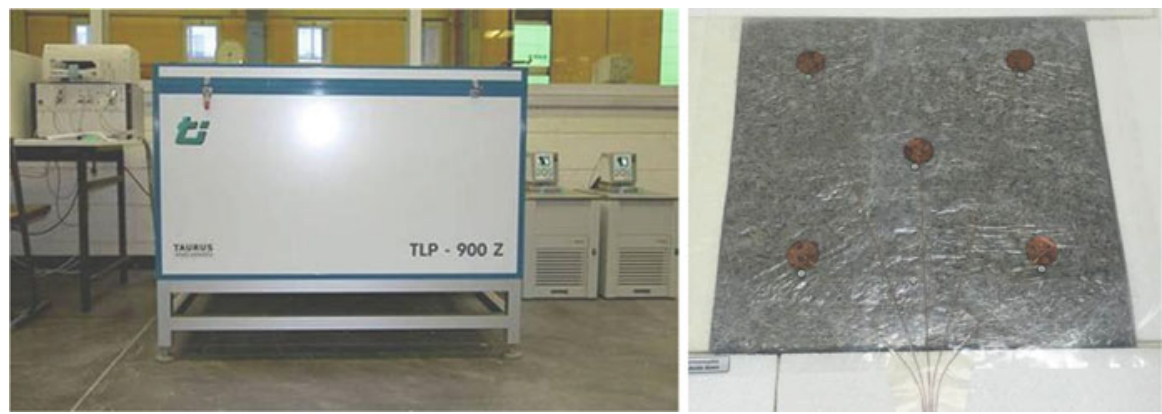

Fig. 23.13 Miscanthus board installed in a guarded hot plate (two-plate device from Taurus instruments)

density due to the industrial production process as the introduced compression and vibration energy during casting in production lines for masonry blocks is much higher.

\section{Description of the Measurement of the Thermal Conductivity of Miscanthus Concrete}

For selected Miscanthus concrete mixtures, two plates of dimensions 50/50/7 cm were produced and the thermal conductivity was determined using the Two-Plate Method according to DIN 52612, DIN EN 122664 and DIN EN 1946-1. This method allows determining the thermal conductivity of homogeneous and inhomogeneous test specimens (Fig. 23.13).

In this method, two samples of the same concrete mixture are placed and analysed such that the direction of the heat flow in the samples corresponds to those in the masonry. The samples are arranged between one heating plate and one cooling plate according to the sequence shown in Fig. 23.14 and a heat flow is established.

Once a stationary temperature state is installed during the measurement, a constant heat flow circulates through the sample plates and a one-dimensional temperature field in the measurement zone is given. The actual heat conductivity is measured by the determination of the electrical power of the mean temperature difference between the sample surface and the physical dimension of the specimen.

This method was applied to several Miscanthus concrete mixtures with different apparent densities and the results were projected in a diagram (Fig. 23.15) showing the relation of the apparent density and the thermal conductivity. Additionally, an approximated line representing the relation is drawn by assuming a linear relation.

As from previous figures, the minimal required apparent density is about $800 \mathrm{~kg} /$ $\mathrm{m}^{3}$, the value for the corresponding thermal conductivity is determined by following the relation line. The associated thermal conductivity value is about $0.17 \mathrm{~W} / \mathrm{mK}$ 


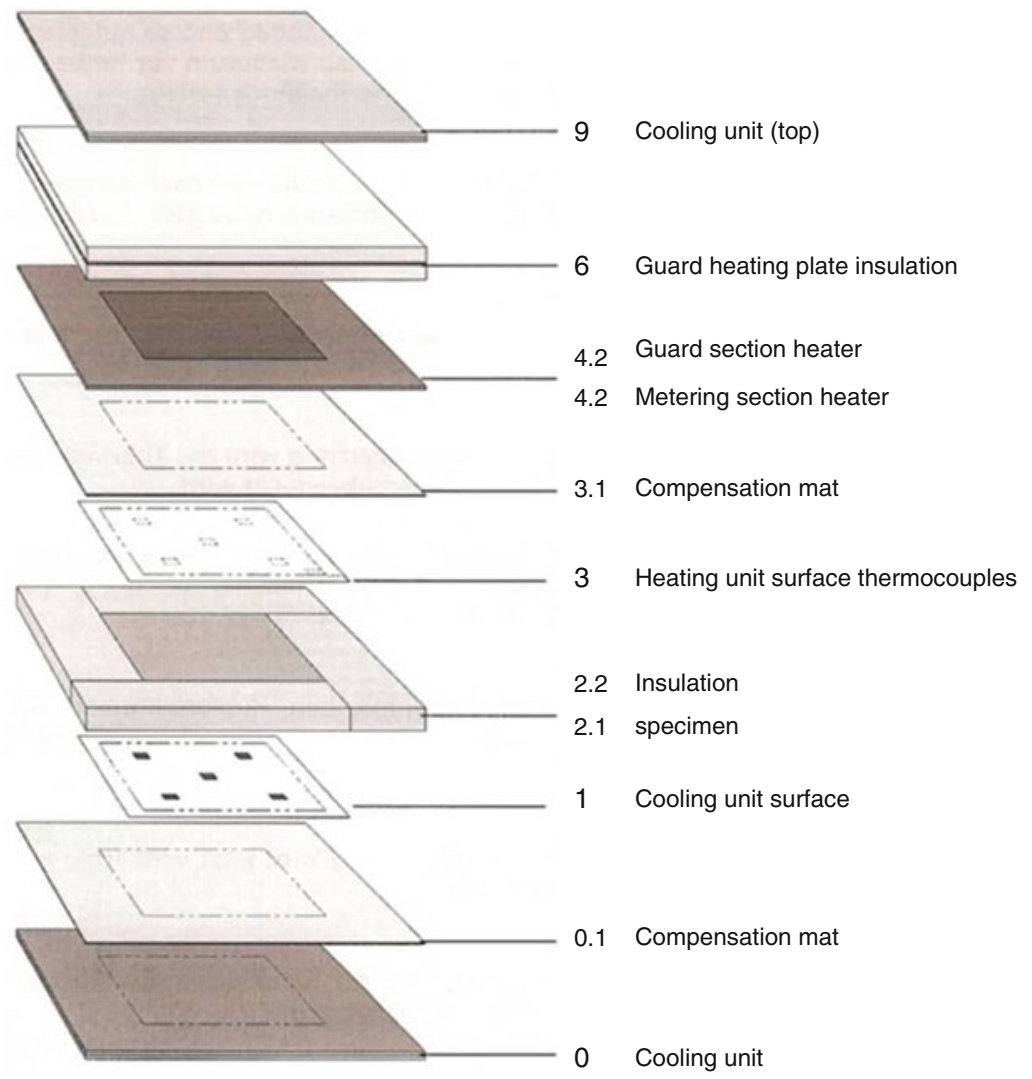

Fig. 23.14 Experimental setup for the measurement of thermal conductivity according to the Two-Plate Method (Taurus Instruments, user's guide 2005)

(Fig. 23.15). Now applying this value of $17 \mathrm{~W} / \mathrm{mK}$ for the thermal conductivity of Miscanthus concrete, the thermal transmission coefficients for varying concrete block configurations can be calculated.

\section{Analytical and Numerical Analysis of the Overall Heat Transfer Resistance for a Given Block Configuration}

In Fig. 23.16 an example of an insulating masonry block configuration with its three layers is given by a top view: the inner load carrying part which is oriented towards the inside of a building, the middle insulation part and the outer leaf forming a resistant outer finish of the wall. The apparent densities with the according heat conductivities are also indicated in Fig. 23.16. The outer shell is realised with the same concrete as the inner load carrying part of the block. 


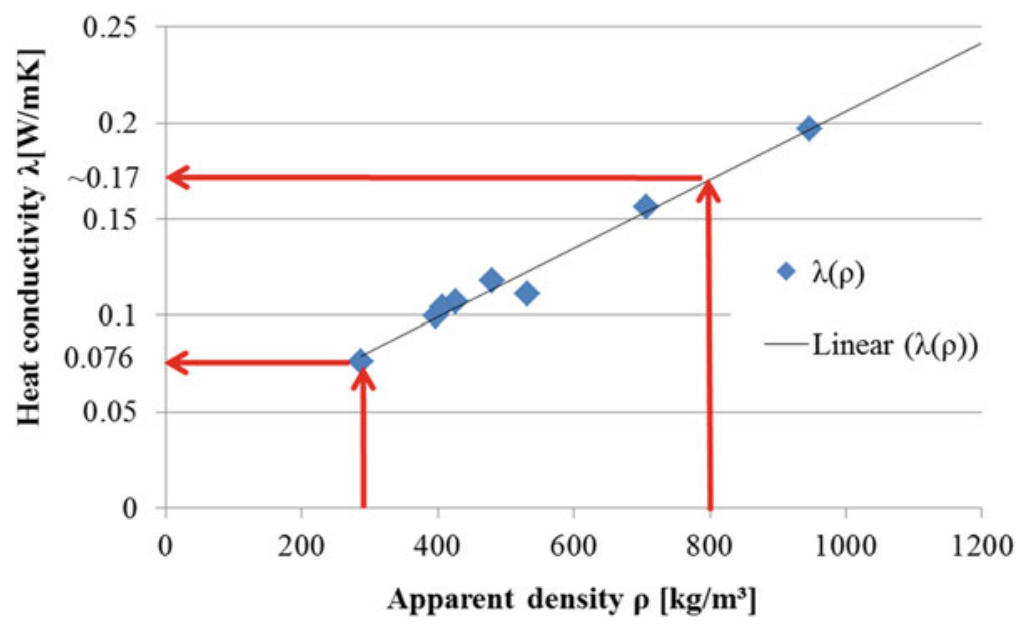

Fig. 23.15 Variation of the thermal conductivity as a function of the apparent density

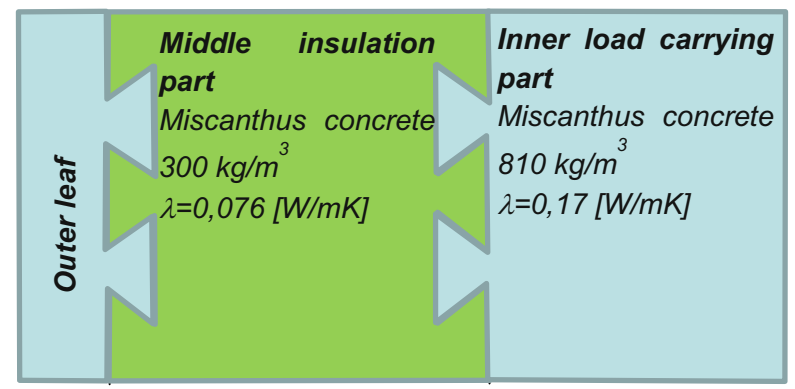

Fig. 23.16 Top view of a possible block configuration

The analytical calculation of the overall heat transfer resistance was performed using a two-dimensional model for the insulation block. The heat transfer resistance is composed of two parts:

1. $\mathrm{RT}^{\prime}=$ the upper extreme: analysis of the heat flow perpendicular to the element surface

2. $\mathrm{RT}^{\prime \prime}=$ the lower extreme: analysis of the heat flow parallel to the element surface

The overall heat transfer resistance is then calculated as follows:

$\mathrm{RT}=\left(\mathrm{RT}^{\prime}+\mathrm{RT}^{\prime \prime}\right) / 2$

These calculated values were used as reference values as additionally a numerical FE calculation is executed in order to check the acceptance of the primary test calculation. This has been realised by using an idealised 3D model in the software 


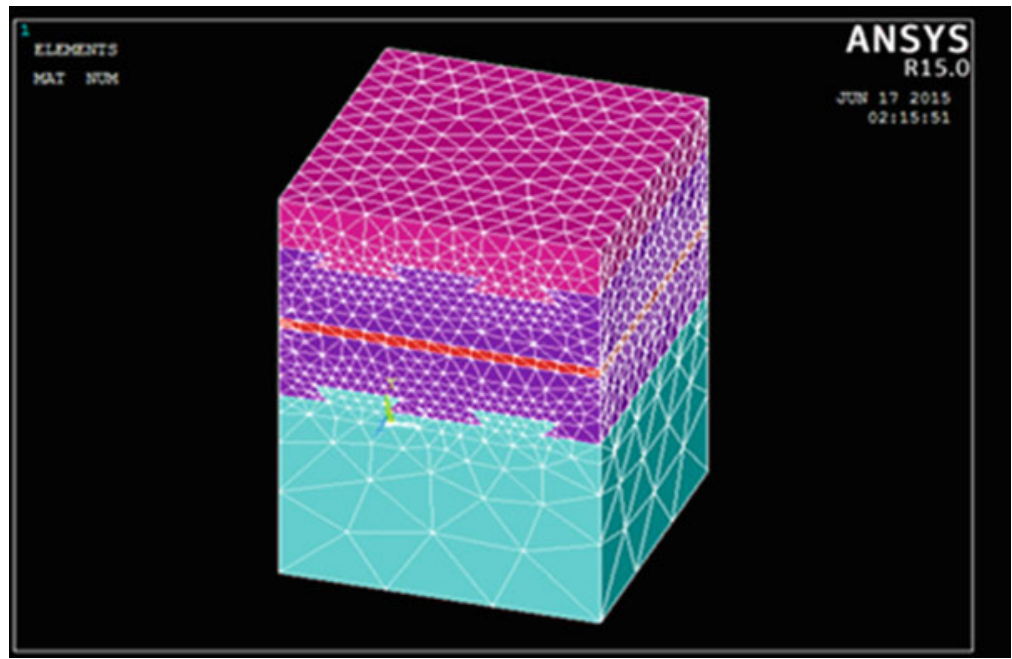

Fig. 23.17 Finite Element Model of an insulating masonry block

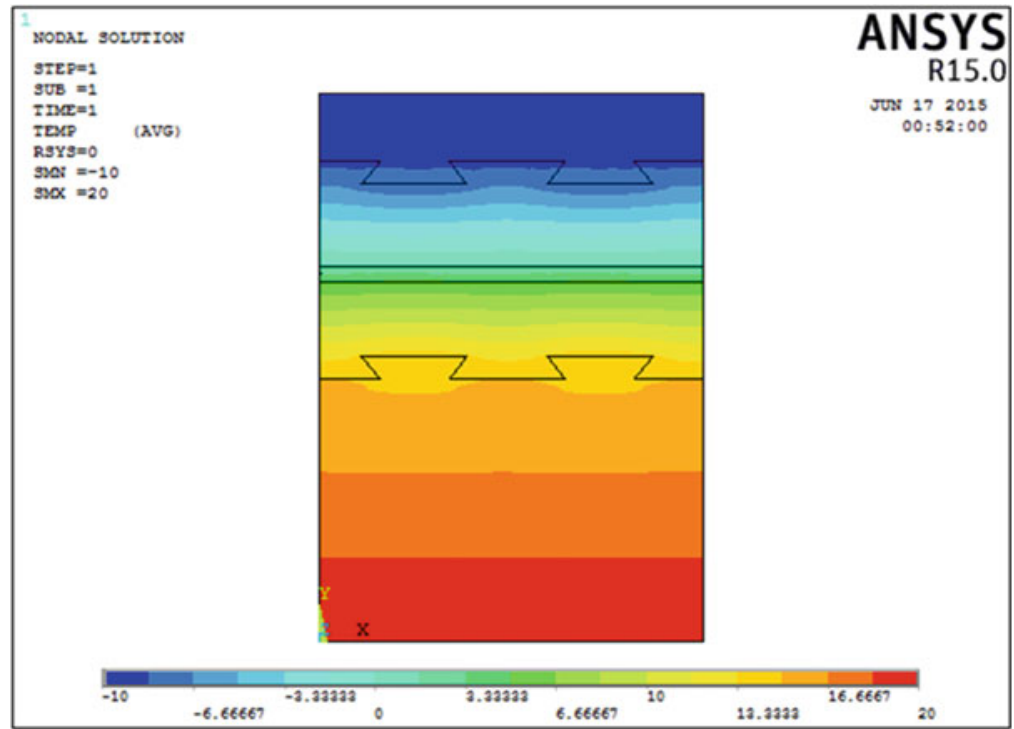

Fig. 23.18 Heat flow through an insulating masonry block

ANSYS on the basis of the Solid90 elements within a steady state analysis (Figs. 23.17 and 23.18). The following parameters have been used:

- Units: $[\mathrm{m}] ;\left[{ }^{\circ} \mathrm{C}\right],[\mathrm{W}],\left[\mathrm{W} / \mathrm{m}^{2} \mathrm{~K}\right]$

- Internal temperature: $+20^{\circ} \mathrm{C}$

- External temperature: $-10^{\circ} \mathrm{C}$

- Internal heat transfer coefficient: $8 \mathrm{~W} / \mathrm{m}^{2} \mathrm{~K}$

- External heat transfer coefficient: $20 \mathrm{~W} / \mathrm{m}^{2} \mathrm{~K}$ 
Table 23.2 Heat transfer resistance of different block configurations

\begin{tabular}{|c|c|c|c|}
\hline \multicolumn{2}{|l|}{ Block configuration } & Heat conductivity $\lambda$ in $[\mathrm{W} / \mathrm{mK}]$ & $\begin{array}{l}\text { Heat transfer resistance } \\
{\left[\mathrm{W} /\left(\mathrm{m}^{2} \mathrm{~K}\right)\right]}\end{array}$ \\
\hline \multirow{2}{*}{$\begin{array}{l}\text { The inner load carrying } \\
\text { block }\end{array}$} & \multirow[t]{2}{*}{$17.5 \mathrm{~cm}$} & Miscanthus concrete $810 \mathrm{~kg} / \mathrm{m}^{3}$ & \multirow[t]{6}{*}{0.312} \\
\hline & & $\lambda=0.17 \mathrm{~W} / \mathrm{mK}$ & \\
\hline \multirow[t]{2}{*}{ Insulation } & \multirow[t]{2}{*}{$15 \mathrm{~cm}$} & $\begin{array}{l}\text { Miscanthus concrete } 300 \mathrm{~kg} / \\
\mathrm{m}^{3}\end{array}$ & \\
\hline & & $\lambda=0.076 \mathrm{~W} / \mathrm{mK}$ & \\
\hline Outer leaf & $4 \mathrm{~cm}$ & Miscanthus concrete $810 \mathrm{~kg} / \mathrm{m}^{3}$ & \\
\hline Total block width & $36.5 \mathrm{~cm}$ & $\lambda=0.17 \mathrm{~W} / \mathrm{mK}$ & \\
\hline \multirow{2}{*}{$\begin{array}{l}\text { The inner load carrying } \\
\text { block }\end{array}$} & \multirow[t]{2}{*}{$17.5 \mathrm{~cm}$} & Miscanthus concrete $810 \mathrm{~kg} / \mathrm{m}^{3}$ & \multirow[t]{6}{*}{0.192} \\
\hline & & $\lambda=0.17 \mathrm{~W} / \mathrm{mK}$ & \\
\hline \multirow[t]{2}{*}{ Insulation } & \multirow[t]{2}{*}{$15 \mathrm{~cm}$} & Standard polystyrene & \\
\hline & & $\lambda=0.035 \mathrm{~W} / \mathrm{mK}$ & \\
\hline Outer leaf & $4 \mathrm{~cm}$ & Miscanthus concrete $810 \mathrm{~kg} / \mathrm{m}^{3}$ & \\
\hline Total block width & $36.5 \mathrm{~cm}$ & $\lambda=0.17 \mathrm{~W} / \mathrm{mK}$ & \\
\hline \multirow{2}{*}{$\begin{array}{l}\text { The inner load carrying } \\
\text { block }\end{array}$} & \multirow[t]{2}{*}{$17.5 \mathrm{~cm}$} & Miscanthus concrete $810 \mathrm{~kg} / \mathrm{m}^{3}$ & \multirow[t]{6}{*}{0.259} \\
\hline & & $\lambda=0.17 \mathrm{~W} / \mathrm{mK}$ & \\
\hline \multirow[t]{2}{*}{ Insulation } & \multirow[t]{2}{*}{$20 \mathrm{~cm}$} & $\begin{array}{l}\text { Miscanthus concrete } 300 \mathrm{~kg} / \\
\mathrm{m}^{3}\end{array}$ & \\
\hline & & $\lambda=0.076 \mathrm{~W} / \mathrm{mK}$ & \\
\hline Outer leaf & $4 \mathrm{~cm}$ & Miscanthus concrete $810 \mathrm{~kg} / \mathrm{m}^{3}$ & \\
\hline Total block width & $41.5 \mathrm{~cm}$ & $\lambda=0.17 \mathrm{~W} / \mathrm{mK}$ & \\
\hline \multirow{2}{*}{$\begin{array}{l}\text { The inner load carrying } \\
\text { block }\end{array}$} & \multirow[t]{2}{*}{$17.5 \mathrm{~cm}$} & Miscanthus concrete $810 \mathrm{~kg} / \mathrm{m}^{3}$ & \multirow[t]{6}{*}{0.150} \\
\hline & & $\lambda=0.17 \mathrm{~W} / \mathrm{mK}$ & \\
\hline \multirow[t]{2}{*}{ Insulation } & \multirow[t]{2}{*}{$20 \mathrm{~cm}$} & Standard polystyrene & \\
\hline & & $\lambda=0.035 \mathrm{~W} / \mathrm{mK}$ & \\
\hline Outer leaf & $4 \mathrm{~cm}$ & Miscanthus concrete $810 \mathrm{~kg} / \mathrm{m}^{3}$ & \\
\hline Total block width & $41.5 \mathrm{~cm}$ & $\lambda=0.17 \mathrm{~W} / \mathrm{mK}$ & \\
\hline
\end{tabular}

Table 23.2 finally shows the results for the heat transfer of the analysed masonry block as a function of varying insulation thickness $(15$ and $20 \mathrm{~cm})$ and insulation performance $(\lambda=0.076 \mathrm{~W} / \mathrm{mK}$ for Miscanthus concrete and $\lambda=0.035 \mathrm{~W} / \mathrm{mK}$ for standard polystyrene). The corresponding heat transfer resistance is indicated in the last column. The variations show heat transfer resistances from 0.312 to $0.15 \mathrm{~W} /$ $\left(\mathrm{m}^{2} \mathrm{~K}\right)$ which constitutes an interesting performance.

\section{Conclusions}

Different masonry insulation block concepts and characteristics have been discussed in order to find the most suitable concepts in terms of insulation performances using Miscanthus lightweight concrete blocks. It has been proven that the compression 
strength that could be reached by lightweight concrete based on Miscanthus aggregates is comparable to other lightweight concrete mixtures. Furthermore, the porous character of this aggregate permits to generate interesting thermal conductivity performances. Thus, this new material is appropriate to be used as basis for masonry insulation blocks.

\section{References}

Achtziger J, Irmschler H.-J (2000) Bestimmung der Rechenwerte der Wärmeleitfähigkeit für Mauerwerk durch Messungen und durch Berechnungen Erschienen in: Mauwerkskalender, Abschnitt D, Teil IV, S. $635 \mathrm{ff}$

Anton H (1992) Bestimmung des Wärmedurchlasswiderstandes von Außenwänden aus MauerwerkVergleich zwischen experimenteller Untersuchung und Berechnung nach der Finiten Differenzen Methode, Final report, Forschungsinstitut für Wärmeschutz München (FIW), DIBt Az:IV $1-5-453 / 85$

Brauer N, Heinecke S (2007) Neues Bemessungskonzept und seine Anwendung in der Baupraxis, Bemessung im Mauerwerksbau, Erschienen in: Deutsches-Ingenieurblatt

Dehn F (1998) Particular features on the production of lightweight aggregate concrete (LAC) with open structure. Lacer No. 03, Institut für Massivbau und Baustofftechnologie, University of Leipzig

DIBt-Richtlinie zur Messung der Wärmeleitfähigkeit $\lambda_{10, \text { tr }}$ von Mauersteinproben, Fassung Oktober 2002, Erschienen in: DIBt-Mitteilungen 2/2003

EuroLightCon-Report No. 1; Definition and International Consensus Report EuroLightCon; Economic Design and Construction with Light Weight Aggregate Concrete; Document BE963942/R1, April 1998

EuroLightCon-Report No. 2; LWAC Material Properties; State-of-the-Art; EuroLightCon; Economic Design and Construction with Light Weight Aggregate Concrete; Document BE963942/R2, December 1998

EuroLightCon-Report No. 8; Properties of lightweight concretes containing Lytag and Liapor, EuroLightCon; Economic Design and Construction with Light Weight Aggregate Concrete; Document BE96-3942/R8, March 2000

European Directive 2010/31/EU of the European Parliament and of the council of 19 May 2010 on the energy performance of buildings

Goltermann P (2008) Load-carrying capacity of lightly reinforced, prefabricated walls of lightweight aggregate concrete with open structure, Materials and Structures, Rilem

Kvande T (2001) Investigations of some Material Properties for Structural Analysis of LECA Masonry, Norwegian University of Science and Technology, Faculty of Civil Engineering, Dissertation

Leufgens N (2010) PhD Thesis Mechanische und thermische Untersuchungen zur Entwicklung eines Wärmedämmsteines aus Leichtbeton. PhD-FSTC-11_2010

Leufgens N, Waldmann D, Maas S, Zürbes A (2007) Development of hybrid-light concrete bricks with improved heat-insulating properties. Third Scottish Conference of Postgraduate Researchers of the Built and Natural Environment, PRoBE 2007, Conference Proceedings, pp. 277-289

Leufgens N, Waldmann D, Maas S, Zürbes A (2009) Thermische und Mechanische Eigenschaftswerte von haufwerksporigen Leichtbetonen (LAC) zur Optimierung von Wärmedämmsteinen, Tagungsband, ibausil -Internationale Baustofftagung, Bauhaus-Universität Weimar 
Sagmeister B (1999) Mauersteine- Wärmedämmend mit haufwerksporigen Leichtbeton, Erschienen in: Betonwerk + Fertigteiltechnik, Heft 7, Vol 65, Bauverlag GmbH Wiesbaden, S. $48-55$

Spitzner J (1975) Haufwerksporige Leichtbetone aus Blähton; Erschienen in: Beton, Heft 3, S. 92-94

Taurus instruments (2005) GmbH, Benutzerhandbuch, TLP 900 Z, Version Juni 2005

Dahm, Faltz (2015) Bachelor Thesis "Machbarkeitsstudie - Miscanthus", Bachelor Professional of Engineering, University of Luxembourg, not published

Voß K-U (2009) Target optimization of high thermal insulation lightweight aggregate concrete with open structure. Proceedings of the 53rd BetonTage- Building the Future- Ulm (Vol. 75, S. 112-113). Concrete Plant + Precast Technology

\section{Standards}

DIN EN 1946-1, Thermal performance of building products and components-Specific criteria for the assessment of laboratories measuring heat transfer properties-Part 1: Common criteria; German version EN 1946-1:1999

DIN 52612: Tesing of thermal insulating materials; determination of thermal conductivity by means of the guarded hot plate apparatus; conversion of the measured values for building applications

DIN EN 12664:2001, Thermal performance of building materials and products—Determination of thermal resistance by means of guarded hot plate and heat flow meter methods-Dry and moist products with medium and low thermal resistance; Beuth Verlag GmbH, May 2001

DIN EN 196, Methods of testing cement—Part 1: Determination of strength; German version EN 196-1:2005

DIN V 18151;4 Lightweight concrete hollow blocks; Deutsches Institut für Normung e.V., Beuth Verlag Berlin, Oktober 2003

DIN V 18152; Lightweight concrete solid blocks; Deutsches Institut für Normung e.V., Beuth Verlag Berlin, Oktober 2003 